\title{
Inferring intentions from biological motion: A stimulus set of point-light communicative interactions
}

\author{
VAleria Manera \\ University of Turin, Turin, Italy \\ and University of Leuven, Leuven, Belgium \\ Ben SCHOUTEN \\ University of Leuven, Leuven, Belgium \\ Cristina Becchio and Bruno G. Bara \\ University of Turin, Turin, Italy \\ AND \\ KarL Verfaillie \\ University of Leuven, Leuven, Belgium
}

\begin{abstract}
We present the first database of communicative interactions reproduced through point-light displays (Communicative Interaction Database). The database contains 20 communicative interactions performed by male and by female couples. For each action, we provide movie files from four different viewpoints, as well as text files with the 3-D spatial coordinates of the point lights, allowing researchers to construct customized versions. By including various types of actions performed with different social motives, the database contains a diverse sample of nonconventional communicative gestures. Normative data collected to assess the recognizability of the stimuli suggest that, for most action stimuli, information in point-light displays is sufficient for clear recognition of the action as communicative, as well as for identification of the specific communicative gesture performed by the actor. The full set of stimuli may be downloaded from http://brm.psychonomic-journals.org/ content/supplemental and from http://ppw.kuleuven.be/labexppsy/lepSite/resources/CID.rar.
\end{abstract}

For human beings, communicative possibilities are not confined to a limited number of signals, as they are for many other species. Every action can, in principle, become a communicative signal. The only prerequisite is that the action is intended as communicative by the actor and is recognized as such by the partner (Bara, 2010). The point of communication is to alter the mental state of the person one is communicating with-for instance, by imparting new knowledge. To be receptive to this new knowledge, the partner has to be able to perceive the speaker's intention to communicate (Sperber \& Wilson, 1995). So conceived, (1) communication acts always occur in the context of a social interaction with a partner; (2) they are overt, in the sense that they are intended to be recognized by the partner; and (3) their satisfaction consists precisely in the fact that they are recognized by the partner (Grice, 1989). By implementing these three requirements, our aim was to construct the first set of moving stimuli involving communicative human interactions under point-light conditions.
The point-light technique is a method for representing human movement through limited visual information. With this method, the movements of a body are represented by a small number of point lights indicating the major joints of a moving person. Despite this drastic degradation of the stimulus, the available information has proven to be sufficient for the recognition of actions (e.g., Dittrich, 1993; Vanrie \& Verfaillie, 2004), as well as different variations of a particular action (e.g., Hoenkamp, 1978; Pollick, Fidopiastis, \& Braden, 2001), and for determination of the identity of a figure (e.g., Cutting \& Kozlowski, 1977; Loula, Prasad, Harber, \& Shiffrar, 2005), his/her gender (e.g., Brooks et al., 2008; Kozlowski \& Cutting, 1977; Pollick, Kay, Heim, \& Stringer, 2005; Troje, 2002), his/her age (Montpare \& ZebrowitzMcArthur, 1988), and his/her emotional state (e.g., Atkinson, Dittrich, Gemmell, \& Young, 2004; Clarke, Bradshaw, Field, Hampson, \& Rose, 2005; Dittrich, Troscianko, Lea, \& Morgan, 1996; Pollick, Paterson, Bruderlin, \& Sanford, 2001). 
In the present work, the point-light technique was used to create a set of 20 communicative interactions performed by a couple of male actors and by a couple of female actors, as seen from different viewpoints. Following Dekeyser, Verfaillie, and Vanrie (2002), stimuli were constructed combining motion capture techniques and animation software. Although other point-light databases including a variety of human actions are available (e.g., Ma, Paterson, \& Pollick, 2006; Shipley \& Brumberg, 2005; Vanrie \& Verfaillie, 2004), none of them contains communication acts.

We are convinced that our stimulus set may constitute a useful tool for researchers working on communication and intentionality, since an important factor in the advancement of those studies is the availability of suitable stimulus material. Intention understanding and communication are core topics of social cognitive neuroscience, a burgeoning interdisciplinary research area in which the researchers seek to understand social phenomena in terms of interactions between the social level, the cognitive level, and the neural level (e.g., Lieberman, 2007; Ochsner \& Lieberman, 2001). Great attention within this area has been devoted to the role played by specific cuessuch as gaze direction and motor kinematics (e.g., Langton, Watt, \& Bruce, 2000; Pierno et al., 2006; Schilbach et al., 2005) - in learning about other people's intentions. A largely debated issue concerns the role of motor cues in understanding communicative intention (e.g., Decety \& Sommerville, 2003; Jacob, 2009; Jacob \& Jeannerod, 2005; Rizzolatti \& Craighero, 2004). Is visual information about body movements per se sufficient to trigger the attribution of a communicative intention? Are movement cues sufficient to discriminate between actions performed with different intents (e.g., individual vs. communicative)? By providing information about movement kinematics without additional information about an actor's shape or structure, the stimuli included in the present database offer a critical opportunity to explore this issue. Three features, in particular, make our database appropriate for studying this issue, as well as other issues in social cognitive neuroscience. First, all the actions included in the present set are nonconventional communicative actions. Whereas conventional communicative gestures, such as the okay sign or the thumbs-up gesture, have a form and a meaning established by the conventions of specific communities and, thus, are recognized as communicative independently from the context in which they are generated, attributing a communicative meaning to nonconventional gestures requires the ability to use motor information to infer the specific communicative intent of the actor. If nonconventional communicative gestures are recognized from pointlight displays, this would indicate that visual information about body movements per se is sufficient for attributing the correct communicative intention. Second, our stimulus set contains movies of a variety of communicative interactions as seen from four different viewpoints. In addition, we make available the 3 -D coordinates of all point-light actions, affording the possibility of constructing pointlight versions of the actions as seen from any desired vantage point. This is an advantage, since previous studies have suggested that action representations are viewpoint dependent (e.g., Daems \& Verfaillie, 1999; Olofsson, Nyberg, \& Nilsson, 1997; Verfaillie, 1993, 2000) and that viewpoint might modulate the cortical response to visually presented actions (e.g., Kilner, Marchant, \& Frith, 2006; Perrett et al., 1989). Finally, moving stimuli included in the present set show not only the action of the actor, but also the partner's response. This is important, since communication acts always occur in the context of a social interaction and their satisfaction does not consist in the mere execution of the gesture but in the recognition of the intention by the partner (Grice, 1989).

In the following paragraphs, we first will describe the method used to construct the action stimuli, as well as the conceptual categories from which the stimuli were derived. Normative data collected to assess the recognizability of the stimuli will be provided in the second part of the article.

\section{METHOD}

Point-light stimuli were constructed following the method described by Dekeyser et al. (2002), combining motion capture data and animation software. Since a detailed and extensive discussion of the technical method has been published previously (Dekeyser et al., 2002; Vanrie \& Verfaillie, 2004), we limit the description of the stimulus construction to a summary of the major steps in the process (see Figure 1).

\section{Precapturing Session}

A couple consisting of two male actors and a couple consisting of two female actresses were selected, and each person was asked to select a role (Actor A, performing the communicative gesture vs. Partner B, acting in response), so that, for each couple, the same role was always played by the same person. The actors knew each other well. Each couple was asked to perform 20 communicative interactions. For each interaction, the actors were provided with a short script contextualizing the interaction (see the "Interaction Description" column in Table 1). In order to obtain two comparable versions of the same action, they were asked to follow a gesture description (see the "Gesture Description" column in Table 1). When the interaction included an object (e.g., table, chair, coins, fruits), this was introduced into the scene, so that the actors always acted on a real object.

\section{Motion Capturing}

The actors were positioned at a distance of approximately $2 \mathrm{~m}$, one facing the other. Each actor was wearing 30 reflective spherical markers (placed on anatomical locations specified in Vicon's Body-Builder 3.5 Manual; Oxford Metrics, 1997), and his/her movements were recorded by a Qualisys MacReflex motion capture system (Qualisys; Gothenburg, Sweden), consisting of six $30-\mathrm{Hz}$ position units (i.e., six cameras and corresponding video processors). To guarantee that the partner's reaction matched the actor's communicative gesture in all respects (e.g., timing, position, kinematics), the actions of the members of each couple were captured at the same time. No markers were attached to the objects used in the interaction. 

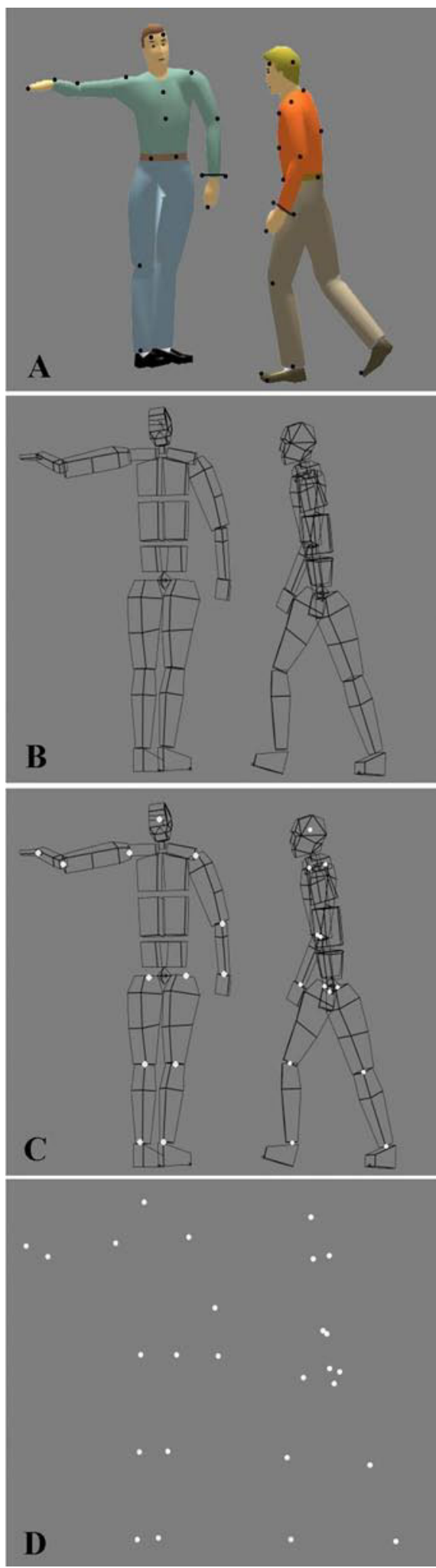

Figure 1. Illustration of the major steps in creating the pointlight stimuli of the Communicative Interaction Database. (A) A schematic drawing of two interacting actors with the 30 visible markers attached to the body. (B) The captured movements are applied to two bipeds in Character Studio. (C) Point lights are attached to the major joints of each biped. (D) The resulting point-light stimuli.

\section{Data Processing}

After the capture session, the 2-D data from all the position units were processed offline to calculate the 3-D coordinates of the markers. The data from the markers were imported in Character Studio (Autodesk, 1998), a software package that was created for use with 3D Studio MAX (Autodesk, 1997). This allowed us to animate a biped for each actor, consisting of a transparent skeleton and 13 bright dots attached to the center of the major joints (shoulders, elbows, wrists, hips, knees, and ankles) and the head. Next, 3-D coordinates for each of the 13 dots for all the frames constituting each actor's action were extracted, and some manual smoothing was performed to avoid any remaining "jumpy" dot movements. To create the actual movie files, the smoothed data were imported into 3D Studio as moving bright spheres, and all the frames of the action were rendered as avi files from four different viewpoints. An orthographic projection was used, and there was no occlusion, so no explicit depth cues were available.

\section{STIMULI}

The database consists of a rar archive that contains 20 folders, 1 for each of the actions listed in Table 1. Action folders contain coordinate files and movie files depicting the same communicative interaction as seen from different perspectives and executed by the two different couples. The database can be retrieved as a supplement from the Psychonomic Society's Web site (http://brm .psychonomic-journals.org/content/supplemental), from the Web site of the Laboratory of Experimental Psychology of the University of Leuven (http://ppw.kuleuven .be/labexppsy/lepSite/resources/CID.rar), or from the Web site of the Center for Cognitive Science of the University and Polytechnic of Turin (www.psych.unito.it/csc/ pers/manera/manera.html).

\section{Actions}

A brief description of each interaction, as well as a description of the communicative gesture made by Agent A, can be found in Table 1. To better characterize each action, three additional classification criteria are provided: nature of the interaction, type of communication act, and social motivation.

Nature of the interaction: Dyadic versus triadic. Whereas some communicative interactions are face-toface interactions (e.g., A asks B to come closer; B comes closer), others require engagement in a person-objectperson interaction (e.g., A asks B to pass him a pen; B passes the pen to A). Following Tomasello, Carpenter, Call, Behne, and Moll (2005), we label the first type of interaction as dyadic and the second type as triadic.

Type of act. In performing a communicative gesture, the actor can have different types of communicative intentions. Following Searle's $(1969,1979)$ "taxonomy of speech acts," actions included in the present database are classified as directives or requestives when the act of the actor is intended to cause the partner to do a particular action (e.g., requests, commands, and advice) and as expres- 
Table 1

Description of the 20 Interactions in the Communicative Interaction Database

\begin{tabular}{|c|c|c|c|c|c|}
\hline Act & Interaction Description & Gesture Description & $\mathrm{D} / \mathrm{T}^{*}$ & Type of Act & Social Motivation \\
\hline Come closer & A asks B to come closer; B comes closer to B. & gesture of the hand & $\mathrm{D}$ & directive & $\begin{array}{l}\text { giving } \\
\text { instructions }\end{array}$ \\
\hline Get down & A asks B to get down; B squats down. & gesture of the hand & $\mathrm{D}$ & directive & ordering \\
\hline $\begin{array}{l}\text { Give that to } \\
\text { me }\end{array}$ & $\begin{array}{l}\text { A asks B for something; B takes it and gives it } \\
\text { to B. }\end{array}$ & $\begin{array}{l}\text { pointing and hold- } \\
\text { ing the hand out }\end{array}$ & $\mathrm{T}$ pen & directive & requesting \\
\hline Go over there & $\begin{array}{l}\text { A asks B to go in that direction; B starts walking } \\
\text { in the indicated direction. }\end{array}$ & $\begin{array}{l}\text { indicating with the } \\
\text { hand }\end{array}$ & $\mathrm{D}$ & directive & ordering \\
\hline Help yourself & $\begin{array}{l}\text { A offers B something making the hand gesture } \\
\text { "help yourself"; B picks the object and eats it. }\end{array}$ & gesture of the hand & T apple & directive & offering \\
\hline I am angry & $\begin{array}{l}\text { A tells B he/she is really angry; B asks A to calm } \\
\text { down. }\end{array}$ & $\begin{array}{l}\text { moving arms and } \\
\text { hands nervously }\end{array}$ & $\mathrm{D}$ & expressive & sharing \\
\hline I am happy & $\begin{array}{l}\text { A tells B he/she is really happy; B shows he/she } \\
\text { is really happy for him/her. }\end{array}$ & $\begin{array}{l}\text { raising arms in } \\
\text { exultation }\end{array}$ & $\mathrm{D}$ & expressive & sharing \\
\hline Imitate me & $\begin{array}{l}\mathrm{A} \text { is doing aerobics, then tells B it is his/her turn; } \\
\mathrm{B} \text { imitates A. }\end{array}$ & pointing & $\mathrm{D}$ & directive & $\begin{array}{l}\text { giving } \\
\text { instructions }\end{array}$ \\
\hline $\begin{array}{l}\text { Look at } \\
\text { that_ceiling }\end{array}$ & $\begin{array}{l}\text { A asks } \mathrm{B} \text { to look at something on the ceiling, } \\
\text { behind } \mathrm{B} ; \mathrm{B} \text { turns } 180^{\circ} \text { and looks at it. }\end{array}$ & pointing & T spider web & directive & sharing \\
\hline $\begin{array}{l}\text { Look at } \\
\text { this_floor }\end{array}$ & $\begin{array}{l}\text { A asks } B \text { to look at something on the floor; } \\
\mathrm{B} \text { bends down to look at it. }\end{array}$ & pointing & T flower & directive & sharing \\
\hline Move it & A asks B to move an object; B moves it. & $\begin{array}{l}\text { indicating with one } \\
\text { hand }\end{array}$ & T flowerpot & directive & requesting \\
\hline Move over & A asks B to move over; B moves over. & $\begin{array}{l}\text { repeated movement } \\
\text { of the hand }\end{array}$ & $\mathrm{D}$ & directive & $\begin{array}{l}\text { giving } \\
\text { instructions }\end{array}$ \\
\hline No & $\begin{array}{l}\text { A says no; B, who was trying to eat something, } \\
\text { puts it down. }\end{array}$ & $\begin{array}{l}\text { gesture of the hand/ } \\
\text { arm }\end{array}$ & T apple & directive & ordering \\
\hline Pick it up & $\begin{array}{l}\text { A indicates to B the position of something on the } \\
\text { floor; B bends down and picks the object up. }\end{array}$ & pointing & $\mathrm{T}$ coin & directive & helping \\
\hline Put it down & $\begin{array}{l}\text { A asks B to put something on the floor; B picks } \\
\text { the object and puts it on the floor. }\end{array}$ & pointing & T box & directive & requesting \\
\hline Sit down & A invites B to sit down; B sits down. & $\begin{array}{l}\text { gesture of the arm/ } \\
\text { hand }\end{array}$ & T chair & directive & ordering \\
\hline Stop & A asks B to stop; B, who is walking, stops. & gesture of the hand & $\mathrm{D}$ & directive & ordering \\
\hline This tall? & $\begin{array}{l}\text { A asks B whether someone is "this tall"; B } \\
\text { shows that he/she is much taller. }\end{array}$ & $\begin{array}{l}\text { indicating with the } \\
\text { hand }\end{array}$ & $\mathrm{D}$ & directive & $\begin{array}{l}\text { requesting } \\
\text { information }\end{array}$ \\
\hline Which one? & $\begin{array}{l}\text { A asks B which one of two objects he/she (B) } \\
\text { wants; B takes one object. }\end{array}$ & holding both objects & $\begin{array}{l}\text { T apple and } \\
\text { pear }\end{array}$ & directive & offering \\
\hline
\end{tabular}

${ }^{*} \mathrm{D}$, dyadic interaction; $\mathrm{T}$, triadic interaction. For triadic interactions, the real objects used in the capturing session are also specified.

sives when the act of the actor expresses attitudes and/or emotions (e.g., congratulations, excuses, and thanks).

Social motivation. Every communication act is an expression of a social motive, representing why an agent performs a specific communicative gesture. A gesture can be performed in order to share emotions or facts, help, ask for help, make a request, ask for information, and so forth. Following the recent proposal of Tomasello, Carpenter, and Liszkowski (2007), each communication act was therefore classified with respect to the underlying social motive. The following categories were included: sharing, requesting, ordering, giving information, requesting information, requesting, helping, and offering.

\section{Coordinate Files}

The coordinate files are listings of the 3-D coordinates of the point lights, saved in different file formats: .txt, .xls, and .pdf. Each action folder contains four coordinate files, representing the actions of the four actors. The filenames have the following structure: action_gender_role, where action is the communicative gesture (listed in Table 1); gender is the gender of the actor ( $\mathrm{M}$ represents males and F females); and role is the role of the actor in the couple (A or B; A is the actor performing the communicative gesture, $\mathrm{B}$ the partner acting in response).

The first line in the files provides the values of three parameters: the number of frames making up the action (dependent on the action), the number of markers (always 13), and the frame rate (always $30 \mathrm{~Hz}$ ). The remainder of the file consists of the 3-D coordinates of the 13 markers for each frame of the action. The first 13 lines give the three spatial coordinates of each of the 13 markers in the first frame, with the first number of each line indicating the width, the second number indicating the depth, and the last number indicating the height. The order of the point lights in the file is as follows: head, two shoulders, two elbows, two wrists, two hips, two knees, and two ankles. The next 13 lines give the coordinates for the second frame, 
and so on. The coupled actions of Actor A and Partner B always have the same number of frames. The 3-D coordinates are centered. That is, the averages of the horizontal, vertical, and depth coordinates of A and B coincide with the center of the coordinate system $(0,0,0)$.

\section{Movie Files}

The movie files consist of point-light actions depicting the two agents of a couple in four different depth orientations: two lateral views (A positioned on the right $\left[90^{\circ}\right]$ and A positioned on the left $\left[270^{\circ}\right]$ ), in which the coronal plane of the two actors is more or less perpendicular to the projection plane, and two three-quarter views (A on the right and seen from the front $\left[125^{\circ}\right]$ and $\mathrm{A}$ on the left seen from the back $\left[305^{\circ}\right]$; see Figure 2). Each action folder contains eight movie files, representing the two couples of actors seen from the four different perspectives. The filenames have the following structure: action_gender orientation, where action is the name of the communicative gesture (listed in Table 1); gender is the gender of the actors ( $\mathrm{M}$ or $\mathrm{F})$; and orientation is the perspective $\left(90^{\circ}\right.$, $125^{\circ}, 270^{\circ}$, and $305^{\circ}$.

The two point-light figures, white against a black background, are approximately equidistant from the center of the screen. Movie files are avi files with a resolution of $640 \times 480$ pixels and a frame rate of 30 frames $/ \mathrm{sec}$.

\section{COLLECTION OF NORMATIVE DATA}

In order to evaluate the efficacy of the stimuli, two types of data were collected. First, we examined how well each stimulus was spontaneously recognized (stimulus identification). Second, we investigated how well naive

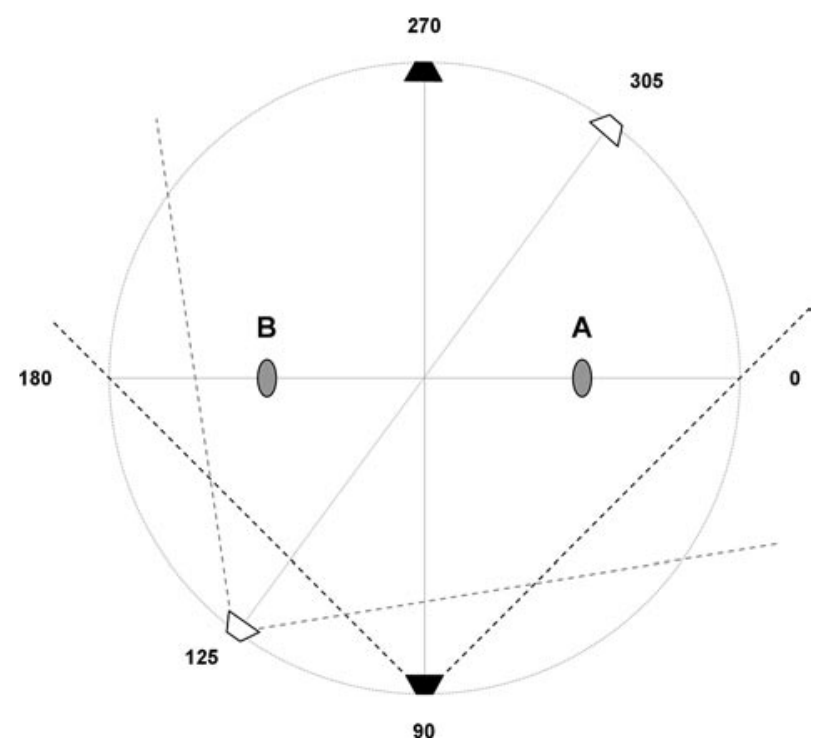

Figure 2. Top view of the different perspectives provided in the movie files for each communicative interaction. $A$ and $B$ are equidistant from the center of the screen and facing each other. The black and white squares represent the available camera views $\left(90^{\circ}, 125^{\circ}, 270^{\circ}\right.$, and $\left.305^{\circ}\right)$. participants judged each action stimulus to match the corresponding description (stimulus verification).

\section{Stimulus Identification}

In order to evaluate spontaneous stimulus identification, action stimuli were shown to 54 students from the Faculty of Psychology at the University of Turin, Italy ( 5 of them male and 49 female; mean age $=23.8$ years, age range $=20-51$ ). All the participants were naive as to the purpose of the study and had no previous experience with point-light displays. The participants were tested in a group, in a semicircular conference room for 100 people (with seats disposed on three semicircular rows), with a central projection screen. Viewing distance ranged from 5 to $8 \mathrm{~m}$. The participants were presented with all 40 stimuli of the Communicative Interaction Database (the 20 communicative interactions performed by two couples of actors; see Table 1). In order to verify whether communicative gestures were clearly distinguishable from noncommunicative gestures, we also presented to the participants 8 noncommunicative control stimuli showing two agents acting independently of each other (see Appendix B). All the action stimuli were constructed following the same procedure (see the Method section), the only difference being that, for control noncommunicative stimuli, the actions of the two agents were captured while the agents acted alone. Each action stimulus consisted of the same action repeated from the four available perspectives. The participants were told that they would be seeing each interaction four times from different perspectives. At the completion of the four movement displays, they were asked, first, to decide whether the two agents were communicating or acting independently of each other and, second, to provide a short description of the actions of both agents. For all the actions, the four perspectives were presented in the order $90^{\circ}, 125^{\circ}, 270^{\circ}$, and $305^{\circ}$, as if the viewing camera, starting from a lateral view, was rotating toward the left.

Scoring procedure. The participants' free reports were scored by a single judge blind as to the purpose of the experiment. She was not shown the movies, but only the action descriptions reported in Table 1, second column. Because communication acts are the focus of our work, for each interaction, she was asked to base her judgment exclusively on the description of the communicative gesture performed by Actor A, without taking into account the description of the response of Partner B. For each action, the judge was asked to decide (1) whether the action had been correctly described as communicative, (2) whether the social motive had been correctly identified, and (3) whether the specific communicative gesture had been identified (see Appendix $\mathrm{C}$ for a detailed report of the scoring procedure). To assess interobserver reliability, a second judge was asked to score independently all the answers of the 54 participants, following the same instructions and procedure as the first judge. The level of agreement between the two judges (calculated using the kappa coefficient; Cohen, 1960) was found to be substantial $(\kappa=.70$; Landis \& Koch, 1977). 
Results. The results of the identification experiment for communicative gestures are listed in Appendix A, and the results of noncommunicative control actions are reported in Appendix B.

The "Communication Act" column in Appendix A indicates the percentage of participants who correctly classified the action stimulus as communicative. On average, the stimuli were correctly recognized as communicative by more than $85 \%$ of the participants (ranging from $15 \%$ to $100 \%$ ). The actions that were less consistently recognized as communicative were "move it" (correctly recognized by $37 \%$ of the participants for the female couple and by $41 \%$ for the male couple) and "this tall?" when performed by the male couple (15\%). Noncommunicative stimuli were classified as communicative only rarely ( $M=13 \%$; see Appendix B), with the exception of "check time," which was interpreted by $50 \%$ of the participants as a communicative "starting" or "out of time" signal.

The "Social Motive" column indicates the percentage of the participants who correctly identified the social motive of the communication acts. On average, the social motive of action stimuli was correctly identified by nearly $74 \%$ of the participants. The action whose social motive was more difficult to identify in both the male and the female versions was "this tall?" (correctly rated by $17 \%$ of the participants for the female couple and by $2 \%$ of the participants for the male couple).

Finally, the "Gesture" column indicates the percentage of the participants who also correctly identified the specific communicative gesture. On average, the communicative gesture of the action stimuli was correctly identified by more than $64 \%$ of the participants (ranging from $0 \%$ to $100 \%$ ). Examples of very well-recognized gestures are "stop," "come closer," and "I am happy," whereas gestures such as "this tall?" "move it," and "help yourself" were more difficult to individuate. Although most of the action stimuli were equally recognizable when performed by the male and by the female couples, some of them were less recognizable in one of the two versions (e.g. "I am angry" and "sit down"). In particular, two actions, "this tall?" and "help yourself," were never recognized when performed by the male and female couple, respectively.

\section{Stimulus Verification}

A second measure of stimulus efficacy was obtained by asking naive participants to evaluate how well, on a 7-point Likert scale, action stimuli matched the descriptions listed in Table 1. Forty-nine psychology students from the University of Turin ( 5 of them male and 44 female; mean age $=19.8$ years, age range $=18-29$ ) volunteered to participate in the experiment. None of them had participated in the stimulus identification experiment. They were tested in a group in the same room as that used for the stimulus identification experiment. We administered to the participants the same actions as those used in the identification experiment (40 communicative interactions and 8 noncommunicative control actions). The action stimuli consisted of a single movie file representing an interaction as seen from a specific perspective. Given that $125^{\circ}$ and $305^{\circ}$ perspectives, as well as $90^{\circ}$ and $270^{\circ}$ perspectives, provide an almost identical view of the stimulus (except that A appears on the opposite side of the screen), we decided to limit the evaluation procedure to two different views, $90^{\circ}$ and $125^{\circ}$. The procedure was as follows. On each trial, the participants were first presented with the action description listed in Table 1 (second column). Then they were shown the action from a specific perspective and were asked to rate how well it could be understood that (1) Agent A was communicating something to Agent B and (2) Actor A was performing the described action. Unlike in the identification session, we obtained separate scores for the $90^{\circ}$ and the $125^{\circ}$ views.

Results. Mean values of the given rating for the first and the second questions are reported in Appendix A (columns 6 and 7, respectively) for the communicative interactions and in Appendix B (columns 6 and 7) for the noncommunicative control actions.

All the communicative gesture stimuli received high ratings for the communicative question (ranging from 4.1 to 6.9 for the different movies), thus confirming that the intention to communicate something was highly identifiable. On the contrary, noncommunicative actions received low ratings for the communicative questions, ranging from 0.8 to 2.8 (see Appendix B).

Concerning the identification of the specific communicative gesture, ratings ranged from 2.9 to 6.9. The least identifiable communicative gesture was "this tall?" with a score between 2.9 and 4.7. Ratings given to the male and female actors were generally very similar $[t(38)=$ $-0.284, p=.778]$, and, in general, the same was true for the two different perspectives $[t(38)=1.144, p=.295]$. However, for some actions (e.g., "go over there" and "I am angry"), identification was better for the lateral view than for the $125^{\circ}$ view. Also, noncommunicative gestures received high ratings for gesture identification (ranging from 4.2 to 6.3 ).

\section{Correlation Between Identification and Verification}

Identification and verification scores for the communicative interactions converge in suggesting that the action stimuli that were recognized better were also evaluated as matching the corresponding description better $[r(38)=$ $.62, p<.001]$. The results of the identification and verification experiments are schematically represented in Figure 3. The different dot colors indicate which of the two action versions (the male or the female one) received higher ratings. For most of the actions, the male and the female versions were given very similar scores; however, some actions received higher ratings in the male version (e.g., "no" and "sit down"), and some others in the female version (e.g., "come closer" and "I am angry").

\section{DISCUSSION}

In order to study the perception of communicative intentions from conspecifics on the basis of visual motion information, we created the first set of point-light communicative interactions. The database includes 20 communicative nonconventional interactions as seen from different 


\section{Normative Data for the CAD Actions}

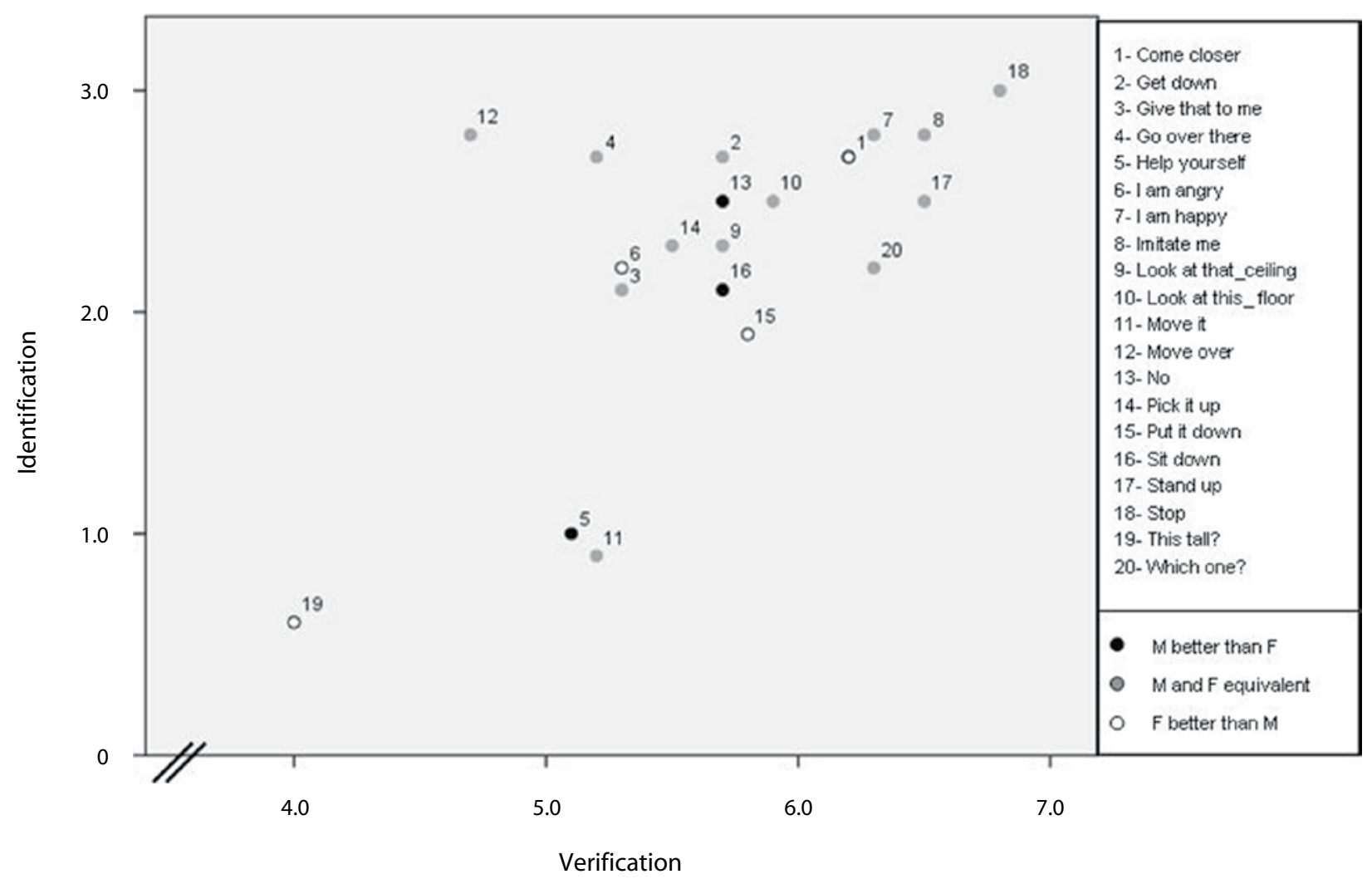

Figure 3. Schematic representation of the normative data for the Communicative Interaction Database. Identification scores are plotted on the ordinate. Scores were ascribed as follows: $0=$ the action was erroneously described as noncommunicative; $1=$ the action was correctly described as communicative, but neither the social motive nor the specific communicative gesture were identified; $\mathbf{2}=$ the action was correctly described as communicative, and the social motive was correctly identified, but the specific gesture was not recognized; 3 = beyond describing the action as communicative and individuating the social motive, the specific communicative gesture also was correctly identified. Mean verification scores are plotted on the abscissa (7-point scale; average between communication acts and specific gesture verification scores). Each dot refers to a different action and represents the mean score attributed to the male and female couples in the different available perspectives. White dots indicate that the female version was scored higher than the male version. Black dots represent the opposite pattern. Gray dots indicate that the male and female versions were given very similar scores.

viewpoints and performed by two different couples of actors. Previous studies have already shown that communicative intentions translate into specific movement patterns (Becchio, Sartori, Bulgheroni, \& Castiello, 2008; Sartori, Becchio, Bara, \& Castiello, 2009). Normative data collected to assess the recognizability of the present stimuli add to these findings, suggesting that, for most of the action stimuli, the information in the point-light displays was indeed sufficient for clear recognition of the action as communicative, as well as for identification of the specific communicative gesture performed by the actor. In line with motor theories of social cognition, these results provide preliminary evidence in favor of the hypothesis that the motor system participates in the understanding of communicative intention (Blakemore \& Decety, 2001; Decety \& Sommerville, 2003; Jacob \& Jeannerod, 2005). Since point-light stimuli have been proven to be well suited for neuroimaging purposes (e.g., Grossman et al., 2000; Peuskens, Vanrie, Verfaillie, \& Orban, 2005; Puce \&
Perrett, 2003), this hypothesis might be directly tested by using the stimuli included in the present database to investigate the neural underpinnings of communicative intention recognition. Since 3-D coordinates of each actor are provided separately, researchers could choose to present a point-light agent performing a communicative gesture in isolation, as well as in the presence of a partner responding in a congruent manner. Social context modulation might be further explored by presenting an agent performing a similar communicative action in the presence of another person responding in an incongruent manner. The veridical or nonveridical social context has been shown to affect emotion recognition from point-light displays (Clarke et al., 2005). Since the satisfaction of communicative intentions consists precisely in the fact that they are recognized by the partner (Grice, 1989), it might be predicted that social context also influences the recognition of communicative gestures. In particular, when the acting partner is absent or acts incongruently, communicative intention 
recognition might be significantly diminished. Finally, the present database might provide a useful tool for exploring the distinction between dyadic and triadic interactions. It has been speculatively proposed that these forms of interaction recruit different regions within the so-called social brain (Saxe, 2006). Comparing point-light face-to-face interactions with person-object-person interaction could constitute a critical test of this hypothesis, helping us to understand what kind of information people can extract from objects that are not visible.

\section{AUTHOR NOTE}

This research was supported by a grant from the Fondazione Cassa di Risparmio di Torino-Progetto Alfieri, and by the Scientific Research Fund Flanders, FWO G.0621.07: audiovisual perception of biological motion. We thank Geoffrey Hamon, Bart Machilsen, and Elisa Gentile for helping in the collection of motion capture data and Adelina Brizio and Michela Allocco for scoring the normative data. Special thanks to Marco Del Giudice and to two anonymous reviewers for their constructive comments and useful advice. Correspondence concerning this article should be addressed to V. Manera, Center for Cognitive Science, Department of Psychology, University of Turin, Via Po 14, 10123 Turin, Italy (e-mail: valeria.manera@unito.it).

\section{REFERENCES}

Atkinson, A. P., Dittrich, W. H., Gemmell, A. J., \& Young, A. W. (2004). Emotion perception from dynamic and static body expressions in point-light and full-light displays. Perception, 33, 717-746. doi: $10.1068 / \mathrm{p} 5096$

Autodesk, InC. (1997). Autodesk 3D Studio Max (Release 2) [Computer software]. Sausalito, CA: Author.

AUTODESK, INC. (1998). Character Studio Max (Release 2) [Computer software]. Sausalito, CA: Author.

BARA, B. G. (2010). Cognitive pragmatics. Cambridge, MA: MIT Press.

Becchio, C., Sartori, L., Bulgheroni, M., \& Castiello, U. (2008). The case of Dr. Jekyll and Mr. Hyde: A kinematic study on social intention. Consciousness \& Cognition, 17, 557-564. doi:10.1016/j .concog.2007.03.003

Blakemore, S.-J., \& Decety, J. (2001). From the perception of action to the understanding of intention. Nature Reviews Neuroscience, 2 , 561-567. doi: $10.1038 / 35086023$

Brooks, A., Schouten, B., Troje, N., Verfaillie, K., Blanke, O., \& VAN DER ZWAN, R. (2008). Correlated changes in perceptions of the gender and orientation of ambiguous biological motion figures. Current Biology, 18, R728-R729. doi:10.1016/j.cub.2008.06.054

Clarke, T. J., Bradshaw, M. F., Field, D. T., Hampson, S. E., \& Rose, D. (2005). The perception of emotion from body movement in point-light displays of interpersonal dialogue. Perception, 34, 11711180. doi: $10.1068 / \mathrm{p} 5203$

Cohen, D. (1960). A coefficient of agreement for nominal scales. Educational \& Psychological Measurement, 20, 37-46.

Cutting, J. E., \& Kozlowski, L. T. (1977). Recognizing friends by their walk: Gait perception without familiarity cues. Bulletin of the Psychonomic Society, 9, 353-356.

Daems, A., \& Verfaillie, K. (1999). Viewpoint-dependent priming effects in the perception of human actions and body postures. Visual Cognition, 6, 665-693. doi:10.1080/135062899394894

Decety, J., \& Sommerville, J. A. (2003). Shared representations between self and other: A social cognitive neuroscience view. Trends in Cognitive Sciences, 7, 527-533. doi:10.1016/j.tics.2003.10.004

Dekeyser, M., Verfaillie, K., \& Vanrie, J. (2002). Creating stimuli for the study of biological-motion perception. Behavior Research Methods, Instruments, \& Computers, 34, 375-382.

DitTRICH, W. H. (1993). Action categories and the perception of biological motion. Perception, 22, 15-22. doi:10.1068/p220015

Dittrich, W. H., Troscianko, T., Lea, S., \& Morgan, D. (1996). Perception of emotion from dynamic point-light displays represented in dance. Perception, 25, 727-738. doi:10.1068/p250727
Grice, H. P. (1989). Studies in the way of words. Cambridge, MA: Harvard University Press.

Grossman, E., Donnelly, M., Price, R., Pickens, D., Morgan, V., NeIghbor, G., \& Blake, R. (2000). Brain areas involved in perception of biological motion. Journal of Cognitive Neuroscience, 12, 711720. doi:10.1162/089892900562417

Hoenkamp, E. (1978). Perceptual cues that determine the labelling of human gait. Journal of Human Movement Studies, 4, 59-69.

JАCOB, P. (2009). The tuning-fork model of human social cognition: A critique. Consciousness \& Cognition, 18, 229-243. doi:10.1016/j .concog.2008.05.002

Jacob, P., \& JeAnNerod, M. (2005). The motor theory of social cognition: A critique. Trends in Cognitive Neurosciences, 9, 21-25. doi:10.1016/j.tics.2004.11.003

Kilner, J. M., Marchant, J. L., \& Frith, C. D. (2006). Modulation of the mirror system by social relevance. Social Cognitive \& Affective Neuroscience, 1, 143-148. doi:10.1093/scan/ns1017

Kozlowski, L. T., \& CutTing, J. E. (1977). Recognizing the sex of a walker from a dynamic point-light display. Perception \& Psychophysics, 21, 575-580.

LandIS, J. R., \& КосH, G. G. (1977). The measurement of observer agreement for categorical data. Biometrics, 33, 159-174.

Langton, S. R. H., WatT, R. J., \& Bruce, V. (2000). Do the eyes have it? Cues to the direction of social attention. Trends in Cognitive Sciences, 4, 50-59. doi:10.1016/S1364-6613(99)01436-9

Lieberman, M. D. (2007). Social cognitive neuroscience: A review of core processes. Annual Review of Psychology, 58, 259-289. doi:10.1146/annurev.psych.58.110405.085654

Loula, F., Prasad, S., Harber, K., \& Shiffrar, M. (2005). Recognizing people from their movement. Journal of Experimental Psychology: Human Perception \& Performance, 31, 210-220. doi:10.1037/0096 $-1523.31 .1 .210$

Ma, Y., Paterson, H. M., \& Pollick, F. E. (2006). A motion capture library for the study of identity, gender, and emotion perception from biological motion. Behavior Research Methods, 38, 134-141.

Montpare, J. M., \& ZebrowitZ-McArThur, L. (1988). Impressions of people created by age-related qualities of their gaits. Journal of Personality \& Social Psychology, 55, 547-556.

Ochsner, K. N., \& Lieberman, M. D. (2001). The emergence of social cognitive neuroscience. American Psychologist, 56, 717-734. doi:10.1037/0003-066X.56.9.717

Olofsson, U., Nyberg, L., \& Nilsson, L. G. (1997). Priming and recognition of human motion patterns. Visual Cognition, 4, 373-382.

Oxford Metrics, LtD. (1997). Body Builder Version 3.5 [Computer software]. Oxford: Author.

Perrett, D. I., Harries, M. H., Bevan, R., Thomas, S., Benson, P. J., MistLIN, A. J., ET AL. (1989). Frameworks of analysis for the neural representation of animate objects and actions. Journal of Experimental Biology, 146, 87-113.

Peuskens, H., Vanrie, J., Verfaillie, K., \& Orban, G. A. (2005). Specificity of regions processing biological motion. European Journal of Neuroscience, 21, 2864-2875. doi:10.1111/j.1460-9568 .2005.04106.x

Pierno, A., Becchio, C., Wall, M. B., Smith, A. T., Turella, L., \& Castiello, U. (2006). When gaze turns into grasp. Journal of Cognitive Neuroscience, 18, 2130-2137. doi:10.1162/jocn.2006.18.12.2130

Pollick, F. E., Fidopiastis, C., \& Braden, V. (2001). Recognizing the style of spatially exaggerated tennis serves. Perception, 30, 323-338. doi: $10.1068 / \mathrm{p} 3064$

Pollick, F. E., Kay, J. W., Heim, K., \& Stringer, R. (2005). Gender recognition from point-light walkers. Journal of Experimental Psychology: Human Perception \& Performance, 31, 1247-1265. doi:10.1037/0096-1523.31.6.1247

Pollick, F. E., Paterson, H. M., Bruderlin, A., \& Sanford, A. J. (2001). Perceiving affect from arm movement. Cognition, 82, B51B61. doi:10.1016/S0010-0277(01)00147-0

Puce, A., \& Perrett, D. (2003). Electrophysiology and brain imaging of biological motion. Philosophical Transactions of the Royal Society $B, \mathbf{3 5 8}, 435-445$. doi: $10.1098 / \mathrm{rstb} .2002 .1221$

Rizzolatti, G., \& Craighero, L. (2004). The mirror neuron system. Annual Review of Neuroscience, 27, 169-192. doi:10.1146/annurev .neuro.27.070203.144230

Sartori, L., Becchio, C., Bara, B. G., \& Castiello, U. (2009). Does 
the intention to communicate affect action kinematics? Consciousness \& Cognition, 18, 766-772.

SAXE, R. (2006). Uniquely human social cognition. Current Opinion in Neurobiology, 16, 235-239. doi:10.1016/j.conb.2006.03.001

Schilbach, L., Wohlschlaeger, A. M., Kraemer, N. C., Newenh, A., Sha, N. J., FinK, G. R., \& Vogeley, K. (2005). Being with virtual others: Neural correlates of social interaction. Neuropsychologia, $\mathbf{4 4}$, 718-730. doi:10.1016/j.neuropsychologia.2005.07.017

Searle, J. R. (1969). Speech acts. Cambridge: Cambridge University Press.

Searle, J. R. (1979). Expression and meaning. Cambridge: Cambridge University Press.

Shipley, T. F., \& BrumberG, J. S. (2005). Markerless motion-capture for point-light displays. Available at http://astro.temple.edu/ tshipley/ mocap/MarkerlessMoCap.pdf.

Sperber, D., \& Wilson, D. (1995). Relevance: Communication and cognition. Oxford: Blackwell.

Tomasello, M., Carpenter, M., Call, J., Behne, T., \& Moll, H. (2005). Understanding and sharing intentions: The origins of cultural cognition. Behavioral \& Brain Sciences, 28, 675-735. doi:10.1017/ S0140525X05000129

Tomasello, M., Carpenter, M., \& Liszkowski, U. (2007). A new look at infant pointing. Child Development, 78, 705-722. doi:10 $.1111 / \mathrm{j} .1467-8624.2007 .01025 . \mathrm{x}$

Troje, N. F. (2002). Decomposing biological motion: A framework for analyses and synthesis of human gait patterns. Journal of Vision, 2, 371-387. doi: $10.1167 / 2.5 .2$

VANRIE, J., \& Verfaillie, K. (2004). Perception of biological motion: A stimulus set of human point-light actions. Behavior Research Methods, Instruments, \& Computers, 36, 625-629.

Verfaillie, K. (1993). Orientation-dependent priming effects in the perception of biological motion. Journal of Experimental Psychology: Human Perception \& Performance, 19, 992-1013. doi:10.1037/0096 $-1523.19 .5 .992$

VerfaILLIE, K. (2000). Visual perception of human locomotion: Priming effects in direction discrimination. Brain \& Cognition, 44, 192-213. doi: $10.1006 /$ brcg. 2000.1228

\section{SUPPLEMENTAL MATERIALS}

The full Communicative Interactions Database discussed in this article may be downloaded from http://brm.psychonomic-journals.org/ content/supplemental.

APPENDIXA

Normative Data for the Communicative Interaction Database: Stimulus Identification and Stimulus Verification

\begin{tabular}{|c|c|c|c|c|c|c|}
\hline \multirow[b]{2}{*}{ Action } & \multirow[b]{2}{*}{ Filename } & \multicolumn{3}{|c|}{$\begin{array}{l}\text { Identification }{ }^{*} \\
(\%)\end{array}$} & \multicolumn{2}{|c|}{$\begin{array}{l}\text { Verification }^{* *} \\
\text { (Mean Scores) }\end{array}$} \\
\hline & & $\begin{array}{c}\text { Communication } \\
\text { Act }\end{array}$ & $\begin{array}{l}\text { Social } \\
\text { Motive }\end{array}$ & Gesture & $\begin{array}{c}\text { Communication } \\
\text { Act }\end{array}$ & Gesture \\
\hline \multirow[t]{4}{*}{ Come closer } & come_closer_F_90 & 100 & 06 & 06 & 6.7 & 6.6 \\
\hline & come_closer_F_125 & 100 & 96 & 96 & 6.6 & 6.5 \\
\hline & come_closer_M_90 & & & & 6.5 & 6.3 \\
\hline & come_closer_M_125 & 89 & 83 & 69 & 5.7 & 5.2 \\
\hline \multirow[t]{4}{*}{ Get down } & get_down_F_90 & 06 & 06 & 03 & 6.5 & 5.9 \\
\hline & get_down_F_125 & 90 & 90 & 93 & 6.1 & 5.0 \\
\hline & get_down_M_90 & 100 & 03 & 59 & 6.6 & 6.0 \\
\hline & get_down_M_125 & & & & 6.4 & 5.9 \\
\hline \multirow[t]{4}{*}{ Give that to me } & give_me_F_90 & 08 & 50 & 18 & 5.7 & 4.9 \\
\hline & give_me_F_125 & 98 & 39 & 48 & 6.3 & 5.3 \\
\hline & give_me_M_90 & 100 & 65 & 57 & 6.4 & 5.6 \\
\hline & give_me_M_125 & 100 & 03 & וד & 6.4 & 5.2 \\
\hline \multirow[t]{4}{*}{ Go over there } & go_overthere_F_90 & & & & 6.3 & 5.7 \\
\hline & go_overthere_F_125 & 100 & 85 & 80 & 5.7 & 4.7 \\
\hline & go_overthere_M_90 & 96 & 87 & 87 & 6.3 & 5.9 \\
\hline & go_overthere_M_125 & 90 & 81 & 81 & 5.6 & 4.3 \\
\hline \multirow[t]{4}{*}{ Help yourself } & help_yourself_F_90 & 30 & 0 & 0 & 5.4 & 5.0 \\
\hline & help_yourself_F_125 & 50 & U & 0 & 5.9 & 5.3 \\
\hline & help_yourself_M_90 & 72 & 54 & 37 & 5.8 & 5.4 \\
\hline & help_yourself_M_125 & 12 & 54 & 31 & 5.3 & 4.7 \\
\hline \multirow[t]{4}{*}{ I am angry } & I_am_angry_F_90 & 98 & 94 & 78 & 6.9 & 6.8 \\
\hline & I_am_angry_F_125 & 98 & 94 & 18 & 6.5 & 5.8 \\
\hline & I_am_angry_M_90 & 81 & 50 & 31 & 5.5 & 4.6 \\
\hline & I_am_angry_M_125 & 81 & 59 & 31 & 5.9 & 3.8 \\
\hline \multirow[t]{4}{*}{ I am happy } & I_am_happy_F_90 & & & & 6.3 & 6.0 \\
\hline & I_am_happy_F_125 & 98 & 96 & 96 & 6.5 & 6.2 \\
\hline & I_am_happy_M_90 & 100 & 87 & & 6.6 & 6.4 \\
\hline & I_am_happy_M_125 & 100 & 87 & 85 & 6.8 & 6.6 \\
\hline \multirow[t]{4}{*}{ Imitate me } & imitate_me_F_90 & 08 & 08 & 60 & 6.6 & 6.5 \\
\hline & imitate_me_F_125 & 98 & 98 & 09 & 6.4 & 6.3 \\
\hline & imitate_me_M_90 & 98 & 98 & 93 & 6.7 & 6.6 \\
\hline & imitate_me_M_125 & & & & 6.6 & 6.4 \\
\hline
\end{tabular}


APPENDIXA (Continued)

\begin{tabular}{|c|c|c|c|c|c|c|}
\hline \multirow[b]{2}{*}{ Action } & \multirow[b]{2}{*}{ Filename } & \multicolumn{3}{|c|}{$\begin{array}{c}\text { Identification* } \\
(\%)\end{array}$} & \multicolumn{2}{|c|}{$\begin{array}{l}\text { Verification** } \\
\text { (Mean Scores) }\end{array}$} \\
\hline & & $\begin{array}{l}\text { Communication } \\
\text { Act }\end{array}$ & $\begin{array}{c}\text { Social } \\
\text { Motive }\end{array}$ & Gesture & $\begin{array}{c}\text { Communication } \\
\text { Act }\end{array}$ & Gesture \\
\hline \multirow[t]{2}{*}{ Look at that_ceiling } & $\begin{array}{l}\text { look_ceiling_F_90 } \\
\text { look_ceiling_F_125 }\end{array}$ & 78 & 72 & 70 & $\begin{array}{l}6.2 \\
6.1\end{array}$ & $\begin{array}{l}5.9 \\
5.6\end{array}$ \\
\hline & $\begin{array}{l}\text { look_ceiling_M_90 } \\
\text { look_ceiling_M_125 }\end{array}$ & 87 & 76 & 74 & $\begin{array}{l}6.2 \\
5.9\end{array}$ & $\begin{array}{l}5.9 \\
5.5\end{array}$ \\
\hline \multirow[t]{2}{*}{ Look at this_floor } & $\begin{array}{l}\text { look_floor_F_90 } \\
\text { look_floor_F_125 }\end{array}$ & 93 & 89 & 72 & $\begin{array}{l}6.1 \\
6.4\end{array}$ & $\begin{array}{l}5.8 \\
5.7\end{array}$ \\
\hline & $\begin{array}{l}\text { look_floor_M_90 } \\
\text { look_floor_M_125 }\end{array}$ & 94 & 85 & 72 & $\begin{array}{l}6.5 \\
6.3\end{array}$ & $\begin{array}{l}5.9 \\
6.2\end{array}$ \\
\hline \multirow[t]{2}{*}{ Move it } & $\begin{array}{l}\text { move_it_F_90 } \\
\text { move_it_F_125 }\end{array}$ & 37 & 28 & 22 & $\begin{array}{l}5.9 \\
5.8\end{array}$ & $\begin{array}{l}5.3 \\
5.2\end{array}$ \\
\hline & $\begin{array}{l}\text { move_it_M_90 } \\
\text { move_it_M_125 }\end{array}$ & 41 & 31 & 28 & $\begin{array}{l}5.7 \\
5.6\end{array}$ & $\begin{array}{l}5.3 \\
4.9\end{array}$ \\
\hline \multirow[t]{2}{*}{ Move over } & $\begin{array}{l}\text { move_over_F_90 } \\
\text { move_over_F_125 }\end{array}$ & 98 & 94 & 80 & $\begin{array}{l}5.4 \\
5.8\end{array}$ & $\begin{array}{l}3.7 \\
5.0\end{array}$ \\
\hline & $\begin{array}{l}\text { move_over_M_90 } \\
\text { move_over_M_125 }\end{array}$ & 100 & 96 & 89 & $\begin{array}{l}5.7 \\
5.9\end{array}$ & $\begin{array}{l}5.3 \\
4.8\end{array}$ \\
\hline \multirow[t]{2}{*}{ No } & $\begin{array}{l}\text { no_F_90 } \\
\text { no_F_125 }\end{array}$ & 81 & 78 & 74 & $\begin{array}{l}5.6 \\
6.2\end{array}$ & $\begin{array}{l}4.3 \\
5.6\end{array}$ \\
\hline & $\begin{array}{l}\text { no_M_90 } \\
\text { no_M_125 }\end{array}$ & 100 & 93 & 83 & $\begin{array}{l}6.7 \\
6.7\end{array}$ & $\begin{array}{l}6.4 \\
6.6\end{array}$ \\
\hline \multirow[t]{2}{*}{ Pick it up } & $\begin{array}{l}\text { pick_up_F_90 } \\
\text { pick_up_F_125 }\end{array}$ & 83 & 81 & 81 & $\begin{array}{l}6.0 \\
6.1\end{array}$ & $\begin{array}{l}5.6 \\
5.5\end{array}$ \\
\hline & $\begin{array}{l}\text { pick_up_M_90 } \\
\text { pick_up_M_125 }\end{array}$ & 81 & 70 & 70 & $\begin{array}{l}5.6 \\
6.1\end{array}$ & $\begin{array}{l}5.1 \\
5.6\end{array}$ \\
\hline \multirow[t]{2}{*}{ Put it down } & $\begin{array}{l}\text { put_down_F_90 } \\
\text { put_down_F_125 }\end{array}$ & 78 & 76 & 70 & $\begin{array}{l}5.9 \\
6.1\end{array}$ & $\begin{array}{l}5.7 \\
5.7\end{array}$ \\
\hline & $\begin{array}{l}\text { put_down_M_90 } \\
\text { put_down_M_125 }\end{array}$ & 81 & 59 & 11 & $\begin{array}{l}6.1 \\
6.4\end{array}$ & $\begin{array}{l}5.8 \\
6.1\end{array}$ \\
\hline \multirow[t]{2}{*}{ Sit down } & $\begin{array}{l}\text { sit_down_F_90 } \\
\text { sit_down_F_125 }\end{array}$ & 61 & 54 & 46 & $\begin{array}{l}5.4 \\
5.8\end{array}$ & $\begin{array}{l}5.1 \\
5.5\end{array}$ \\
\hline & $\begin{array}{l}\text { sit_down_M_90 } \\
\text { sit_down_M_125 }\end{array}$ & 91 & 89 & 80 & $\begin{array}{l}6.3 \\
6.5\end{array}$ & $\begin{array}{l}5.9 \\
6.3\end{array}$ \\
\hline \multirow[t]{2}{*}{ Stand up } & $\begin{array}{l}\text { stand_up_F_990 } \\
\text { stand_up_F_125 }\end{array}$ & 94 & 87 & 80 & $\begin{array}{l}6.4 \\
6.6\end{array}$ & $\begin{array}{l}6.2 \\
6.4\end{array}$ \\
\hline & $\begin{array}{l}\text { stand_up_M_90 } \\
\text { stand_up_M_125 }\end{array}$ & 96 & 76 & 70 & $\begin{array}{l}6.8 \\
6.7\end{array}$ & $\begin{array}{l}6.7 \\
6.7\end{array}$ \\
\hline \multirow[t]{2}{*}{ Stop } & $\begin{array}{l}\text { stop_F_90 } \\
\text { stop_F_125 }\end{array}$ & 100 & 98 & 98 & $\begin{array}{l}6.8 \\
6.9\end{array}$ & $\begin{array}{l}6.8 \\
6.7\end{array}$ \\
\hline & $\begin{array}{l}\text { stop_M_90 } \\
\text { stop_M_125 }\end{array}$ & 100 & 100 & 100 & $\begin{array}{l}6.9 \\
6.8\end{array}$ & $\begin{array}{l}6.9 \\
6.8\end{array}$ \\
\hline \multirow[t]{2}{*}{ This tall? } & $\begin{array}{l}\text { this_tall_F_90 } \\
\text { this_tall_F_125 }\end{array}$ & 72 & 17 & 11 & $\begin{array}{l}5.8 \\
5.5\end{array}$ & $\begin{array}{l}4.7 \\
4.5\end{array}$ \\
\hline & $\begin{array}{l}\text { this_tall_M_90 } \\
\text { this_tall_M_125 }\end{array}$ & 15 & 2 & 0 & $\begin{array}{l}4.1 \\
5.1\end{array}$ & $\begin{array}{l}2.9 \\
3.8\end{array}$ \\
\hline \multirow[t]{2}{*}{ Which one? } & $\begin{array}{l}\text { which_one_F_90 } \\
\text { which_one_F_125 }\end{array}$ & 91 & 63 & 46 & $\begin{array}{l}6.8 \\
6.6\end{array}$ & $\begin{array}{l}6.4 \\
6.0\end{array}$ \\
\hline & $\begin{array}{l}\text { which_one_M_90 } \\
\text { which_one_M_125 }\end{array}$ & 98 & 81 & 67 & $\begin{array}{l}6.7 \\
6.6\end{array}$ & $\begin{array}{l}6.3 \\
6.3\end{array}$ \\
\hline
\end{tabular}

*Sample of 54 participants. Reported values refer to the percentage of participants who correctly identified each feature of the actions (communication act, social motive, and gesture). ${ }^{* *}$ Sample of 49 participants. Reported values refer to the mean scores attributed by participants to each action (score range: $1-7$ ). 


\section{APPENDIX B}

Description and Normative Data for Control Noncommunicative Stimuli: Stimulus Identification and Stimulus Verification

\begin{tabular}{|c|c|c|c|c|c|c|}
\hline \multirow[b]{2}{*}{ Action } & \multirow[b]{2}{*}{ Filename } & \multirow[b]{2}{*}{ Actions Description } & \multicolumn{2}{|c|}{ Identification* (\%) } & \multicolumn{2}{|c|}{$\begin{array}{l}\text { Verification** } \\
\text { (Mean Scores) }\end{array}$} \\
\hline & & & $\begin{array}{l}\text { Communication } \\
\text { Act }\end{array}$ & Gesture & $\begin{array}{l}\text { Communication } \\
\text { Act }\end{array}$ & Gesture \\
\hline Turn & $\begin{array}{l}\text { turn_90 } \\
\text { turn_125 }\end{array}$ & A turns $90^{\circ}$. B squats down. & 9 & 91 & $\begin{array}{l}1.2 \\
1.5\end{array}$ & $\begin{array}{l}6.0 \\
6.0\end{array}$ \\
\hline Jump & $\begin{array}{l}\text { jump_90 } \\
\text { jump_125 }\end{array}$ & $\begin{array}{l}\text { A makes one jump. B bends down } \\
\text { and picks up an object. }\end{array}$ & 0 & 98 & $\begin{array}{l}1.2 \\
0.9\end{array}$ & $\begin{array}{l}6.3 \\
6.2\end{array}$ \\
\hline Look under foot & $\begin{array}{l}\text { look_foot_90 } \\
\text { look_foot_125 }\end{array}$ & $\begin{array}{l}\text { A looks under his/her foot. B draws } \\
\text { an object down, and puts it on the } \\
\text { floor. }\end{array}$ & 4 & 80 & $\begin{array}{l}0.8 \\
0.9\end{array}$ & $\begin{array}{l}6.0 \\
6.2\end{array}$ \\
\hline Check time & $\begin{array}{l}\text { check_time_90 } \\
\text { check_time_125 }\end{array}$ & $\begin{array}{l}\text { A checks the time. B, who is sitting, } \\
\text { stands up. }\end{array}$ & 50 & 22 & $\begin{array}{l}2.8 \\
2.3\end{array}$ & $\begin{array}{l}4.7 \\
5.1\end{array}$ \\
\hline Sneeze & $\begin{array}{l}\text { sneeze_90 } \\
\text { sneeze_125 }\end{array}$ & $\begin{array}{l}\text { A sneezes. B turns him/herself } \\
\left(180^{\circ}\right) \text {. }\end{array}$ & 23 & 72 & $\begin{array}{l}2.2 \\
1.5\end{array}$ & $\begin{array}{l}4.3 \\
5.8\end{array}$ \\
\hline Lateral step & $\begin{array}{l}\text { lateral_step_90 } \\
\text { lateral_step_125 }\end{array}$ & $\begin{array}{l}\text { A makes two lateral steps. B grasps } \\
\text { something in front of him/her and } \\
\text { eats it. }\end{array}$ & 23 & 80 & $\begin{array}{l}1.9 \\
1.7\end{array}$ & $\begin{array}{l}4.6 \\
5.4\end{array}$ \\
\hline Stretching & $\begin{array}{l}\text { stretching_90 } \\
\text { stretching_125 }\end{array}$ & $\begin{array}{l}\text { A makes stretching. B takes an } \\
\text { object and moves it. }\end{array}$ & 11 & 76 & $\begin{array}{l}2.0 \\
1.8\end{array}$ & $\begin{array}{l}4.6 \\
5.4\end{array}$ \\
\hline Drink & $\begin{array}{l}\text { drink_90 } \\
\text { drink_125 }\end{array}$ & $\begin{array}{l}\text { A drinks a glass of water. B sits } \\
\text { down. }\end{array}$ & 2 & 76 & $\begin{array}{l}1.0 \\
0.9\end{array}$ & $\begin{array}{l}5.7 \\
6.0\end{array}$ \\
\hline
\end{tabular}

APPENDIX C

Scoring Criteria and Procedure for Identification Experiment

The judges were provided with the following list of scoring criteria.

"We showed to participants some action stimuli with two actors. In some stimuli the two actors were communicating; in other stimuli they were acting independently of each other. We asked the participants:

1) to evaluate whether the two actors were communicating, or whether they were acting independently of each other;

2) to describe separately what actor A and actor B were doing.

Taking in account only the answer relative to actor $A$ (for each answer of each participant), you need to decide:

a) whether the action had been correctly described as communicative or non-communicative.

Base the score on answers to question 1.

b) if the action had been correctly described as communicative, whether the social motive had been correctly identified.

Base the score on answers to question 2. Compare the social motive underlying the answer with the correct social motive provided in Table 1, column 6.

c) if the social motive had been correctly identified, whether also the specific communicative gesture had been identified.

Base the score on answers to question 2. Compare the answer with the action description reported in Table 1, column 3. An answer should be considered correct when it is identical to the target description, it is a paraphrase of the target description, or it is an over-interpretation of the target description (e.g., it contains details, contextual elements, etc., not provided in the target description).

d) if the action had been correctly described as non-communicative, whether the specific gesture had been correctly identified.

Base the score on answers to question 2. Compare the answer with the action description reported in Appendix B, column 2." 